\title{
Movimento de expansão dos cursos superiores de enfermagem na região centro-oeste do Brasil: uma perspectiva histórica
}

\section{Movement of expansion of the upper courses of nursing in the center-west region of Brazil: a historical perspective}

\section{Movimiento de expansión de los cursos superiores de enfermería en la región centro- oeste del Brasil: una perspectiva histórica}

\author{
Thais Silva Corrêa Barbosa', Suely de Souza Baptista"I
}

\section{RESUMO}

Estudo documental de abordagem histórico social, cujo objeto foi a trajetória de crescimento dos cursos superiores de enfermagem na região Centro-Oeste do Brasil. Os objetivos foram: levantar o número de cursos superiores de enfermagem criados na região Centro-Oeste, na série histórica 19332006; comparar o número de cursos vinculados a instituições públicas aos vinculados a instituições privadas na região em estudo; e comentar os nexos entre o contexto histórico e a configuração desses cursos no que se refere à vinculação institucional, ao longo dos anos. Até o final do ano de 1999, haviam sido criados na região Centro-Oeste 14 cursos de enfermagem, dos quais $57 \%$ eram privados e $43 \%$ públicos. Em decorrência das políticas de educação adotadas no país, principalmente na década de 90, observa-se a criação de mais 30 cursos na região entre os anos 2000 e 2006, perfazendo um total de 44 cursos superiores de enfermagem, dos quais $79,5 \%$ são privados e 20,5\% públicos, sendo Goiás, o estado com maior concentração destes cursos. A rede privada expandiu-se na região e concentra, atualmente, a grande maioria dos cursos de enfermagem, o que nos faz entender que a mesma determina, quase que por completo, o perfil do futuro profissional de enfermagem.

Palavras chave: Enfermagem; História da Enfermagem; Escolas de Enfermagem; Brasil.

\footnotetext{
ABSTRACT

A documentary study with historical social approach, whose object was the nursing upper courses growth path in Center-West region of Brazil. The objectives were: raise the nursing upper courses number created in Center-West region, in the historical series 1933-2006; compare the courses number linked to the public institutions linked to private institutions in region in study; and comment the
}

connections between the historical context and those courses configuration in what refers to the institutional linking, to the long one of the years. Results: to the end of 1999, had been created in the Center-West region 14 nursing courses, of which $57 \%$ were private and $43 \%$ public. In consequence of education politics adopted in the country, mainly in the 90', observes-itself the creation of more 30 courses in region between the years 2000 and 2006, making up a total of 44 nursing upper courses, of which $79,5 \%$ are private and $20,5 \%$ public, being Goiás, the state with bigger concentration of these courses. The private net expanded itself in region and concentrates, at present, to nursing courses big majority, what is going to make us understand that the same determines, barely that completely, the nursing professional future profile.

Key words: Nursing; History of Nursing; School of Nursing; Brazil.

\section{RESUMEN}

Estudio documental con enfoque histórico social, cuyo objeto fue la trayectoria del crecimiento de cursos superiores de enfermería en región Central-Oeste de Brasil. Los objetivos fueron: levantar el número de cursos superiores de enfermería creados en la región Centro-Oeste, en serie histórica 1933-2006; comparar el número de cursos ligado a instituciones públicas y ligados a instituciones privadas en la región

Enfermeira. Mestranda do Programa de Pós-Graduação da Escola de Enfermagem Anna Nery da Universidade Federal do Rio de Janeiro (EEAN/UFRJ). Membro do Núcleo de Pesquisa de História da Enfermagem Brasileira (NUPHEBRAS). Rio de Janeiro/RJ. E-mail: thaisbrj@yahoo.com.br.

Enfermeira. Doutora em História da Enfermagem. Professora Visitante da Faculdade de Enfermagem da Universidade do Estado do Rio de Janeiro (UERj). Pesquisadora do CNPq. Membro Fundador do NUPHEBRAS. Rio de Janeiro/RJ. E-mail: suelybaptista@openlink.com.br 
en estudio; y comentar conexiones entre el contexto histórico y la configuración de esos cursos en lo que se refiere al vínculo institucional, al largo de los años. Resultados: al fin del año de 1999, había sido criados en la región Centro-Oeste 14 cursos de enfermería, del cuál $57 \%$ eran privado y $43 \%$ públicos. Como consecuencia de políticas de educación adoptadas en el país, principalmente en la década de 90 , se observa la criación de más 30 cursos en la región entre 2000 y 2006 , haciendo un suma de 44 cursos superiores de enfermería,

\section{NTRODUÇÃO}

Este estudo documental, de cunho sóciohistórico, tem como objeto a trajetória de crescimento dos cursos superiores de enfermagem na região Centro-Oeste do Brasil. O recorte temporal compreende o período de 1933 a 2006, sendo o marco inicial correspondente ao ano de criação da primeira escola de enfermagem na região Centro-Oeste do Brasil e o final, referente ao ano de término da presente pesquisa.

A escolha do recorte espacial justifica-se pelo fato de o Centro-Oeste ser uma região com extensa área territorial (ficando atrás somente da região Norte); que nas décadas 30,50 e 60 do século $X X$ teve grande impulso ao desenvolvimento através do Programa "Marcha para o Oeste", da criação de Brasília e da Superintendência de Desenvolvimento do Centro-Oeste (SUDECO). Contudo, quanto à criação dos cursos superiores de enfermagem é a região com um dos menores números de cursos do país, sendo a sua expansão registrada principalmente a partir da década de 90, isto é, cinqüenta e sete anos após a criação, em 1933, do primeiro curso na região.

Para alcançar o objeto proposto, os seguintes objetivos foram traçados: levantar o número de cursos superiores de enfermagem criados na região Centro-Oeste, na série histórica 1933-2006; comparar o número de cursos vinculados a instituições públicas aos vinculados a instituições privadas na região em estudo; e comentar os nexos entre o contexto histórico e a configuração desses cursos no que se refere à vinculação institucional, ao longo dos anos. de los cuales $79,5 \%$ son privados y $20,5 \%$ públicos, siendo Goiás, el estado con mayor concentración de estos cursos. La red privada se ensanchó en la región y concentra, en la actualidad, la grande mayoría de cursos de enfermería, lo que nos hace entender que la misma determina, casi que completamente, el perfil del futuro profesional de enfermería.

Palabras clave: Enfermería; Historia de la Enfermería; Escuela de la Enfermería; Brasil.

Para melhor compreender a problemática deste estudo foi indispensável considerar alguns marcos na história do Brasil, principalmente os relacionados aos campos da educação e da saúde, que, direta ou indiretamente, influenciaram na trajetória dos cursos superiores de enfermagem na sociedade brasileira.

As fontes primárias da pesquisa incluem: os dados do site do Instituto Nacional de Estudos e Pesquisas Educacionais Anísio Teixeira - Inep - (http://www.inep.gov.br/), as respostas a questionários aplicados aos cursos de enfermagem em funcionamento na região Centro-Oeste e o anexo com a lista das escolas de enfermagem em funcionamento no Brasil até o ano de 1959 do livro: Enfermagem, Leis, Decretos e Portarias - Serviço Especial de Saúde Pública (SESP) do Ministério da Educação. As fontes secundárias foram obtidas em livros, dissertações, teses, artigos, e sites que abordam a temática, com destaque para as bibliografias referentes à história do Brasil e da enfermagem e às políticas de educação e saúde.

Acreditamos, com este estudo, contribuir para a construção do conhecimento referente à história dos cursos superiores de enfermagem no Centro-Oeste e para a orientação de futuras pesquisas acerca da temática em questão.

\section{A REGI Ão CENTRO-OESTE E AS PRI MEI RAS ESCOLAS DE ENFERMAGEM NO BRASIL: DÉCADAS DE 20, 30 E 40 DO SÉCULO XX}

A primeira tentativa de sistematização do ensino de enfermagem no Brasil ocorreu em 1890, com a criação, na cidade do Rio de Janeiro, da Escola Profissional de Enfermeiros e Enfermeiras do Hospício Nacional de Alienados 
Barbosa TSC, Baptista SS. Movimento de expansão dos cursos superiores de enfermagem na região centro-oeste do Brasil: uma perspectiva histórica. Rev. Eletr. Enf. [Internet]. 2008;10(4):945-56. Available from: http://www.fen.ufg. br/revista/v10/n4/v10n4a07.htm.

(atual Escola de Enfermagem Alfredo Pinto/UNIRIO) ${ }^{(1)}$. Esta escola se baseava no modelo de enfermagem adotado na Europa, influenciado pelos ideais da Revolução Francesa e pelos avanços da psiquiatria na França ${ }^{(2)}$.

No início do século $X X$, um marco significativo para a história do Brasil e do mundo foi a Primeira Guerra Mundial (19141918), cujas repercussões impulsionaram a industrialização do país e, para o ensino de enfermagem, influenciaram na criação de cursos de enfermagem, pela Cruz Vermelha, em 1914, na cidade de São Paulo e em 1916 na cidade do Rio de Janeiro; com a finalidade de preparar voluntárias para atender em situações de emergência, guerra, catástrofes e epidemias ${ }^{(1)}$.

No entanto, a institucionalização do ensino de enfermagem no Brasil, no modelo angloamericano, se deu somente com a criação da Escola de Enfermeiras do Departamento Nacional de Saúde Pública (DNSP), pela Missão Técnica de Cooperação para o Desenvolvimento da Enfermagem no Brasil, chefiada por Ethel O. Parsons, a qual começou a funcionar em fevereiro de 1923. A finalidade imediata da criação desta escola era a formação de enfermeiras de Saúde Pública para atender às exigências de uma situação estrutural, a qual o Brasil enfrentava, e que foi agravada com a Primeira Guerra Mundial ${ }^{(2)}$.

Com a Revolução de 1930, que assinalou o fim da Primeira República, Getúlio Vargas assumiu a presidência de um governo provisório (1930-1934) marcado pelas divergências entre os militares tenentistas e as oligarquias, além de uma nova política de proteção ao café(3).

A partir de 1931, pelo Decreto no 20.109, a escola do DNSP, no mesmo ano denominada Escola de Enfermeiras Anna Nery, foi considerada a escola oficial padrão para efeito de reconhecimento e equiparação de outras escolas de enfermagem que viessem a ser criadas no país ${ }^{(2)}$.

Entretanto, somente dez anos após a inauguração da Escola de Enfermeiras Anna Nery é que surgiram outras escolas de enfermagem no Brasil. Este intervalo de tempo nos faz entender que o governo não teria, com relação a outras cidades brasileiras, os mesmos interesses políticos e econômicos que determinaram a criação da Escola Anna Nery na capital federal $^{(2)}$, à época a cidade do Rio de Janeiro.

Somente no ano de 1933 é que foram inauguradas outras duas escolas de enfermagem no Brasil; ambas de orientação religiosa são elas: Escola de Enfermagem Carlos Chagas (de orientação católica), em Belo Horizonte, no estado de Minas Gerais, a primeira a formar enfermeiras religiosas no Brasil; e a Escola de Enfermagem Florence Nightingale (de orientação evangélica), anexa ao Hospital Evangélico Goiano na cidade de Anápolis, no estado de Goiás. Quanto a esta, a primeira escola criada na região Centro-Oeste, vale acrescentar que em 1925 chegou ao Brasil o casal Dr. James e Ethel Fanstone, que logo percebeu que a situação de saúde pública no país estava muito afetada pelas endemias, como a tuberculose e a febre amarela. Preocupado com as questões de saúde, Dr. James Fanstone obteve dos presbiterianos o apoio necessário para o desenvolvimento de seus projetos missionários e em 1927 inaugurou - Hospital Evangélico Goiano(4). A criação da Escola de Enfermagem Florence Nightingale (inaugurada em 12 de agosto de 1933) ocorreu devido à necessidade de que o hospital tivesse enfermeiras capacitadas para a assistência à população.

Em meados de 1930 foi criado na cidade de Rio Verde, também no estado de Goiás, um Hospital Evangélico, e em 1937 uma escola de enfermagem a ele vinculada. Cabe dizer que, este hospital foi fundado mediante a intensa dedicação do Dr. Donald Covil Gordon, médico missionário enviado pela Presbyterian Church $(P C)$, dos Estados Unidos, para a Missão Brasil Central e da sua esposa, Helen Gary Gordon ${ }^{(6)}$.

Em 1937, o Estado Novo (1937-1945) foi implantado. Período fortemente marcado pelo poder intervencionista do Estado, representado novamente por Getúlio Vargas, que buscava incentivos ao processo de industrialização, economia dependente e renda concentrada. Com relação à educação, Getúlio Vargas a enxergava como um pilar para sustentar sua imagem pública, disseminar a sua doutrina e, assim, moldar a opinião pública ${ }^{(3)}$. 
Barbosa TSC, Baptista SS. Movimento de expansão dos cursos superiores de enfermagem na região centro-oeste do Brasil: uma perspectiva histórica. Rev. Eletr. Enf. [Internet]. 2008;10(4):945-56. Available from: http://www.fen.ufg. br/revista/v10/n4/v10n4a07.htm.

Nas vésperas de 1938, foi lançada a "Marcha para o Oeste"; uma política colonizadora de Getúlio Vargas para desenvolver o interior do Brasil, pois, o país, com extenso território, havia prosperado quase que exclusivamente na região litorânea, mantendo o vasto interior estagnado - vítima da política mercantilista colonial, da falta de estradas viáveis e de rios navegáveis, do liberalismo econômico e do sistema federalista que caracterizaram a Velha República (18891930). Mais de $90 \%$ da população brasileira ocupava cerca de um terço do território nacional, sendo as regiões Centro-Oeste e Norte esparsamente povoadas ${ }^{(7)}$.

Outro ponto importante a destacar durante o Estado Novo foi o grande apoio da Igreja Católica ao Governo de Getúlio Vargas, que em troca tomou medidas importantes que favoreceram, dentre outras coisas, o ensino religioso nas escolas públicas. Assim, o Estado, ao permitir a atuação dos religiosos católicos, recebia apoio para se manter autoritário e no poder. E o clero, por sua vez, se aproveitou das vantagens a ele oferecidas e tratou de criar uma série de instituições de nível superior, inclusive de enfermagem, garantindo, assim, a formação de enfermeiras com base na doutrina católica ${ }^{(8)}$.

Foi neste contexto que a terceira escola de enfermagem da região Centro-Oeste foi criada, no início da década de 40, na cidade de Goiânia/GO. De orientação religiosa católica (Associação São Vicente de Paulo), denominava-se Escola de Enfermagem do Hospital São Vicente de Paulo(5).

Cabe destacar que, até aquele momento, as escolas de enfermagem na região CentroOeste foram criadas somente no estado de Goiás, levando-se em consideração que a mesma era composta, naquela ocasião, apenas pelos estados de Goiás e Mato Grosso.

Para que se possa compreender esta concentração de cursos no estado, é oportuno ressaltar que Goiás, após a sua fundação, muito prosperou devido à riqueza de suas minas. Com o fim do ciclo do ouro, a agropecuária ampliouse, principalmente com a criação de gado, transformando o estado em um importante produtor. Outros ramos da economia também se desenvolveram na região, como a indústria e o comércio ${ }^{(9)}$. Além disso, tem-se a construção da cidade planejada de Goiânia no ano de 1933, e que em 1937 passou a ser a capital. Tais fatos, determinaram maiores investimentos em infra-estrutura no estado e portanto, no maior desenvolvimento e concentração populacional, quando comparado ao estado de Mato Grosso.

No ano de 1943, um fato importante na região Centro-Oeste, que determinou a diminuição da área territorial do até então estado de Mato Grosso, foi o Decreto-Lei no 5.812 , de 13 de setembro, que criou o Território Federal de Guaporé, unindo terras dos estados de Mato Grosso e Amazonas(10), e que atualmente é o estado de Rondônia. Dentre outros motivos, a intenção desta divisão foi a de apoiar mais diretamente a ocupação e o desenvolvimento da região.

Já no governo do General Eurico Gaspar Dutra (1946-1951), em 6 de agosto de 1949, foi aprovada a Lei no 775 que deu uma nova orientação ao ensino e enfermagem, pois o dividiu em dois cursos, o de enfermagem e o de auxiliar de enfermagem; além disso, cessou a exigência de equiparação de novas escolas à escola padrão, sendo a partir desta lei, competência da Diretoria de Ensino Superior do Ministério da Educação e Saúde a verificação para o funcionamento e posterior reconhecimento das escolas; instituiu a obrigatoriedade de vinculação das escolas de enfermagem a centros universitários ou à faculdades de medicina(11) e estabeleceu a exigência do curso secundário completo para o ingresso de alunos nos cursos de enfermagem $^{(2)}$, no entanto, esta última exigência foi prorrogada por duas vezes, o que acabou permitindo a entrada de estudantes apenas com o curso ginasial até o ano de 1961.

No final da década de 40, havia no Brasil vinte e três cursos superiores de enfermagem; dos quais, treze $(56,5 \%)$ eram privados e mantidos por congregações religiosas (sendo, $84,6 \%$ católicos e $15,4 \%$ evangélicos) e dez $(43,5 \%)$ públicos, mantidos pelo governo federal ou estadual. A distribuição geográfica destes cursos era a seguinte: Sudeste concentrava quatorze $(61 \%)$ cursos, sendo sete $(50 \%)$ de orientação católica; Nordeste cinco $(22 \%)$, dos quais três $(60 \%)$ eram de 
orientação católica; Centro-Oeste três (13\%), sendo um $(33,3 \%)$ católico; e Norte um $(4 \%)$, público ${ }^{(5)}$.

Durante o Estado Novo, observou-se um aumento do número de cursos de enfermagem, grande parte deles de orientação religiosa e vinculada a hospitais, ao contrário do que preconizavam as enfermeiras norte-americanas, que organizaram o ensino de enfermagem na Escola de Enfermeiras Anna Nery. Especificamente no Centro-Oeste, esta realidade ficou clara quando discutimos a criação das três primeiras escolas de enfermagem na região.

\section{AS ESCOLAS DE ENFERMAGEM BRASI LEI RAS - ANOS 50 E 60 DO SÉCULO XX}

Em 31 de janeiro de 1956 tomou posse como presidente da República Juscelino Kubitschek de Oliveira - JK - (1956-1961). O seu governo foi marcado por intenso e acelerado crescimento econômico: "cinqüenta anos de progresso em cinco de governo".

Delineada no Plano de Metas, a política econômica de JK abrangia 31 objetivos, distribuídos em grandes grupos: educação, energia, transportes, alimentação, indústrias de base e a construção de Brasília, chamada de meta-síntese. Esta política baseava-se na realização de investimentos diretos, quase sempre precedidos de intensa emissão monetária; o que posteriormente agravou o processo inflacionário.

O fato mais importante da gestão de JK foi a construção de Brasília e a mudança da capital do país para a nova cidade, uma vez que, desde a primeira constituição republicana já constava um dispositivo que previa a mudança da Capital Federal do Rio de Janeiro para o interior do país. Cumprindo a promessa feita em 1955, durante um comício, JK inaugurou em 21 de abril de 1960 a cidade de Brasília, localizada no território do Distrito Federal, e a tornou a nova capital da República Federativa do Brasil (a 3a capital do país). A partir da data de inauguração, iniciou-se a transferência, para a nova capital, dos principais órgãos da administração federal situados, até então, na cidade do Rio de Janeiro.
A construção de Brasília, como sede do governo brasileiro, contribuiu significativamente para o povoamento e o desenvolvimento sócioeconômico da região Centro-Oeste e foi um marco no processo de interiorização do território brasileiro. Quanto ao processo de colonização do Oeste do Brasil, é importante acrescentar que o mesmo, naquele momento, representou uma válvula de escape, na medida em que tinha como um dos objetivos absorver os excedentes demográficos das áreas rurais mais valorizadas do Sul e Sudeste do país ${ }^{(12)}$.

Com a criação de Brasília, era de se pensar que novos cursos de enfermagem fossem criados no Centro-Oeste. Todavia, verificou-se que, durante as décadas de 50 e 60 , nenhum curso foi criado na região, mesmo sendo observadas excelentes condições para a expansão do ensino de enfermagem, como por exemplo: a estabilidade política, o crescimento econômico e o processo de povoamento impulsionado pela construção/inauguração da capital federal - Brasília.

Em contrapartida, nas demais regiões do país o número de cursos de enfermagem continuou crescendo, tanto que, ao final de 1959, o número de cursos passou de vinte três (ao final de 1949) para trinta e oito. Destes trinta e oito, vinte e quatro $(63,2 \%)$ eram privados (sendo, 91,7\% de orientação católica e $8,3 \%$ evangélica) e quatorze $(36,8 \%)$ públicos ${ }^{(5)}$.

Cabe dizer que na década de 50 foram criados onze cursos de enfermagem de orientação católica ${ }^{(5)}$; o que demonstra que nos governos subseqüentes a Vargas houve a continuidade de uma forte aliança entre o Estado e a I greja.

Além disso, o aumento dos cursos de enfermagem neste período se deu atrelado ao aumento do número de hospitais, como forma de diminuir a problemática da quantidade de enfermeiros nestes locais como também de absorver mão-de-obra mais barata ${ }^{(11)}$.

Com o fim do "Estado Novo", ressurge a luta pelo ensino público e gratuito, uma luta que durou quinze anos e que acabou em um acordo consagrado na Lei de Diretrizes e Bases da Educação Nacional (LDB) de 1961, que definiu e regularizou o sistema de educação brasileiro 
Barbosa TSC, Baptista SS. Movimento de expansão dos cursos superiores de enfermagem na região centro-oeste do Brasil: uma perspectiva histórica. Rev. Eletr. Enf. [Internet]. 2008;10(4):945-56. Available from: http://www.fen.ufg. br/revista/v10/n4/v10n4a07.htm.

com base nos princípios presentes na constituição. No que se refere à educação superior, a LDB rompeu com o regime de exceção da escolaridade mínima e passou a exigir, para a matrícula no curso de graduação, o curso colegial ou equivalente ${ }^{(2)}$.

Politicamente no Brasil, no início de 1964, a crise atingiu todo o país, associado a este fato o descontentamento dos setores empresariais com a política econômica nacionalista do governo de J oão Goulart (1961-1964) tornou-se mais acentuado.

Foi neste contexto que na madrugada do dia 31 de março de 1964, um golpe militar foi deflagrado contra o governo legalmente constituído de Goulart. Com o golpe, teve início a implantação de um regime político marcado pelo "autoritarismo"(3).

Dentro do ideário desenvolvimentista, em 1967 foi criada a Superintendência de Desenvolvimento do Centro-Oeste (SUDECO), que deu prioridade à política rodoviária de eixos de penetração, voltada para o escoamento da produção e integração da região a São Paulo(12).

No que concerne à educação no Brasil, em 1968, estando o General Costa e Silva na condição de representante dos militares na presidência da República, o Congresso Nacional aprovou a Lei da Reforma Universitária, sob o $\mathrm{n}^{\circ}$ 5.540, em 28 de novembro de 1968 (RU/68), a qual fixou normas de organização e funcionamento do ensino superior.

Para a enfermagem, a RU/68 representou mudanças significativas, pois rompeu com o modelo de ensino de enfermagem vigente até então ${ }^{(2)}$.

Pelos achados, no transcorrer da década de 60, cinco cursos de enfermagem foram criados no Brasil, sendo 3 privados e 2 públicos. Cabe frisar que a discreta expansão dos cursos de enfermagem na década de 60 não privilegiou as regiões Norte e Centro-Oeste do Brasil ${ }^{(13)}$.

E ainda com relação ao Centro-Oeste, vale dizer que as escolas de enfermagem criadas na cidade de Rio Verde (GO) e em Anápolis (GO), extinguiram os seus cursos superiores de enfermagem, visto ter entrado em vigor, através da LDB de 1961, a exigência do secundário completo para o ingresso nas escolas de enfermagem. Contudo, estas escolas continuaram em funcionamento, sendo oferecidos pela escola de Anápolis os cursos de auxiliar e técnico de enfermagem, criados nas décadas de 1950 e 1970, respectivamente, e pela escola de Rio Verde o curso de auxiliar de enfermagem, criado na década de 1960.

Devido à extinção de dois dos três cursos superiores de enfermagem oferecidos na região Centro-Oeste, a Escola de Enfermagem do Hospital São Vicente de Paulo passou a ser a única na região responsável, naquele período, pela formação de enfermeiros.

Como panorama dos cursos de enfermagem, observa-se, ao final de 1969, que havia em todo o Brasil quarenta e três cursos superiores de enfermagem, sendo vinte e sete $(63 \%)$ vinculados ao setor privado e dezesseis (37\%) ao setor público ${ }^{(13)}$.

A justificativa para o baixo número de cursos de enfermagem criados no Brasil na década de 60 atribui-se ao fato de que o governo, a partir de 1964, estava voltado para o crescimento e controle político-ideológico, sendo necessário, portanto, o crescimento econômico para atingir o ambicioso desenvolvimento. Nesse sentido, a educação e a saúde passaram a ser definidas como áreas secundárias no planejamento estatal ${ }^{(1)}$.

\section{OS CURSOS DE ENFERMAGEM BRASILEIROS: DÉCADAS DE 70 E 80 DO SÉCULO XX}

Em 1972, o Plano Decenal de Saúde para as Américas traçou como uma de suas metas aumentar o quantitativo de enfermeiros, sendo para isso necessário a ampliação do número de vagas e a abertura de novas escolas de enfermagem no país. Para tanto, o Departamento de Assunto Universitários (DAU/MEC) designou um grupo de enfermeiras, que integrava o Grupo Setorial de Saúde (GSS) deste Departamento, para prestar assessoramento no diagnóstico sobre os cursos de enfermagem no Brasil(14).

Uma das metas do GSS era a dominância do ensino público e gratuito; fosse através do investimento para incentivar o aumento do número de vagas em cursos de enfermagem já existentes ou pela criação de cursos em 
Barbosa TSC, Baptista SS. Movimento de expansão dos cursos superiores de enfermagem na região centro-oeste do Brasil: uma perspectiva histórica. Rev. Eletr. Enf. [Internet]. 2008;10(4):945-56. Available from: http://www.fen.ufg. br/revista/v10/n4/v10n4a07.htm.

universidades federais que ainda não os possuíssem ${ }^{(14)}$.

No setor econômico, a partir de 1974, a economia no Brasil mostrou, mais claramente, os reflexos da crise econômica do capitalismo mundial. Com o fim do "milagre econômico", o governo passou a valorizar a formação de recursos humanos enquanto força de trabalho, agora fundamentando-se na idéia de que o investimento nesta esfera contribuiria para o desenvolvimento econômico ${ }^{(1)}$.

Nesta perspectiva, os setores de educação e saúde passaram a merecer atenção prioritária na medida em que foram considerados como setores que implicavam na qualidade da força de trabalho e contribuíam para atenuar as tensões sociais ${ }^{(1)}$.

Essa ênfase na reprodução da força de trabalho e as metas do Plano Decenal de Saúde para as Américas implicaram na criação de novos cursos superiores de enfermagem no Brasil; sendo criados somente na década de 70 quarenta e quatro cursos superiores, dos quais, vinte e cinco $(57 \%)$ eram públicos e dezenove $(43 \%)$ privados $^{(13)}$.

Foi neste contexto que, no ano de 1975, três novos cursos superiores de enfermagem foram criados no Centro-Oeste, sendo todos mantidos por instituições de ensino federais e localizados: um na Universidade de Brasília (UnB), um na Universidade Federal de Mato Grosso (UFMT) em Cuiabá, e um na Universidade Federal de Goiás (UFG) em Goiânia.

É importante acrescentar que, apesar da criação destes três cursos de enfermagem, o processo de expansão no Centro-Oeste não seguiu o mesmo ritmo das demais regiões brasileiras, por se tratar, dentre outros motivos, de uma região ainda em desenvolvimento, quando comparada ao Sudeste e Sul do Brasil.

Ainda que uma das metas do GSS fosse a dominância do ensino público e gratuito, em 1976 houve um grande incentivo à privatização do ensino superior com a criação, pelo governo federal, do Programa Crédito Educativo (Creduc). Este programa foi criado com a justificativa de oferecer mais um incentivo para a criação de novas vagas no ensino superior. No qual, o governo pagava o ensino do aluno nas instituições privadas e este, depois de formado, assumia o compromisso de devolvê-lo.

Com o golpe de 1964, os militares adotaram a política do desenvolvimento com segurança, permitindo, assim, a criação de programas que facilitaram o desenvolvimento de alguns estados brasileiros, dentre eles o de Mato Grosso ${ }^{(15)}$.

Nesse período, os políticos que integravam o movimento divisionista aproximaram-se dos militares; o que lhes permitiu tomar conhecimento de algumas comissões que estudavam as potencialidades políticas que impediam a divisão do Mato Grosso. Somente após acordos políticos e negociações, o então Presidente Ernesto Geisel assinou, em 11 de outubro de 1977, a Lei Complementar no 31, que criou o Estado de Mato Grosso do Sul ${ }^{(15)}$. De acordo com o governo federal, a divisão do estado resultou da dificuldade de administrar a região diante da sua diversidade e extensão territorial. Assim, a região Centro-Oeste passou a ser composta pelos seguintes estados: Goiás, Mato Grosso, Mato Grosso do Sul e o Distrito Federal.

Em 1984, passados 20 anos desde o golpe de 1964, a insatisfação da sociedade brasileira culminou em uma grande reivindicação política pelas eleições diretas para Presidente da República. A proposta de uma emenda à Constituição restabelecendo eleições diretas sensibilizou o país do norte ao sul ${ }^{(3)}$.

Em abril de 1984 a emenda constitucional foi votada, contudo, faltaram 22 votos favoráveis para completar os dois terços necessários para a sua aprovação. Com a derrota da emenda, os partidos de oposição iniciaram articulações visando abater o regime no próprio colégio eleitoral. Foi assim que em janeiro de 1985, na eleição que encerrava o período de regime militar no país, Tancredo Neves derrotou o candidato Paulo Maluf no colégio eleitoral. Contudo, o presidente eleito, Tancredo Neves, não pôde assumir o cargo por motivo de grave doença que o levou à morte em 21 de abril de 1985, sendo empossado em seu lugar o vice-presidente José Sarney, que iniciou o período conhecido como Nova República $^{(3)}$. 
Barbosa TSC, Baptista SS. Movimento de expansão dos cursos superiores de enfermagem na região centro-oeste do Brasil: uma perspectiva histórica. Rev. Eletr. Enf. [Internet]. 2008;10(4):945-56. Available from: http://www.fen.ufg. br/revista/v10/n4/v10n4a07.htm.

Com a democracia, tempo de grande expectativa nacional, o país se libertou do regime autoritário e promulgou, em 05 de outubro de 1988, sua Constituição Federal (CF).

Neste período, em Goiás, as lideranças do norte do estado aproveitaram o momento para mobilizar a população em torno de um projeto pelo qual muitas gerações lutaram: a autonomia política do norte do estado(16). Vale dizer que com a promulgação da CF de 1988 aproximadamente $40 \%$ da área norte do território de Goiás foi desmembrada, originando o estado de Tocantins ${ }^{(9)}$, localizado, atualmente, na região Norte do país. As justificativas para a separação do norte em relação ao centro-sul de Goiás e instalação de um governo independente eram de natureza econômica, política, administrativa e geográfica; uma vez que os nortistas reclamavam da situação de abandono, exploração econômica e descaso administrativo; e não acreditavam no desenvolvimento da região sem o seu desligamento do sul.

Para o setor de educação, a nova Constituição manteve o princípio segundo o qual "o ensino é livre à iniciativa privada", desde que atendidas às normas gerais da educação nacional. A ausência de leis que especificassem o entendimento de autonomia e o próprio caráter auto-explicativo desse princípio constitucional concederam à iniciativa privada liberdade, associada à agilidade exigida pelo mercado, em questões como abertura e extinção de cursos e diminuição e ampliação do número de vagas ${ }^{(17)}$.

Vale ressaltar que no Brasil a década de 80 foi marcada por uma política extremamente recessiva e com intensa retração dos gastos públicos, o que privilegiou o avanço da rede privada. Como resultado desta expansão temos, nesta década, a criação de vinte e oito cursos superiores de enfermagem no território nacional, sendo vinte e um $(75 \%)$ privados e sete $(25 \%)$ públicos ${ }^{(13)}$.

Assim, ao final do ano de 1989, haviam sido criados no Brasil cento e dezesseis cursos superiores de enfermagem, dos quais sessenta e nove $(59,5 \%)$ eram privados e quarenta e sete $(40,5 \%)$ públicos. A distribuição espacial era a seguinte: região Sudeste - cinqüenta e sete cursos $(49,1 \%)$ : quarenta e dois privados
(74\%) e quinze públicos (26\%); região Sul vinte e seis cursos $(22,4 \%)$ : quinze privados $(58 \%)$ e onze públicos (42\%); região Nordeste - vinte e um cursos $(18,1 \%)$ : quatorze públicos $(67 \%)$ e sete privados (33\%); região Norte seis cursos $(5,2 \%)$ : cinco públicos $(83 \%)$ e um privado $(17 \%)$ e região Centro-Oeste - seis cursos $(5,2 \%)$ : três públicos $(50 \%)$ e três privados $(50 \%)^{(13)}$.

\section{NOVOS TEMPOS: DÉCADA DE 90 DO SÉCULO XX}

Ao assumir a presidência, o caráter neoliberal do discurso de Fernando Collor de Mello - FCM - (1990-1992), advogando, principalmente, o fim do intervencionismo estatal em assuntos econômicos, contribuiu para aglutinar setores das classes dirigentes em torno de sua proposta ${ }^{(3)}$.

A suspeita de que, o então presidente Collor, estivesse envolvimento em um amplo esquema de corrupção e tráfico de influência fizeram com que o Congresso Nacional instaurasse em 1992 uma Comissão Parlamentar de Inquérito (CPI), para investigar as denúncias contra Paulo César Farias, extesoureiro da campanha presidencial de FCM e que ainda mantinha vínculos com o governo. $O$ relatório final da CPI apontou ligações estreitas entre o presidente e o empresário, iniciando-se a partir daí um processo de impeachment contra o então presidente, que logo após perdeu o seu mandato ${ }^{(3)}$.

Itamar Franco, vice-presidente, assumiu o cargo de Presidente da República (1992-1994), herdando os graves problemas econômicos e sociais de seu antecessor. Em matéria de política econômica, a realização mais relevante do novo governo foi a instituição do Plano Real, pelo então Ministro da Fazenda Fernando Henrique Cardoso, cujas principais metas eram: reduzir a inflação e estabilizar a econômica ${ }^{(3)}$.

Em 1995, Fernando Henrique Cardoso (FHC) assumiu a presidência do Brasil e para este mesmo cargo foi reeleito pelo período de 1999-2002. Em seu primeiro mandato (19951998), no âmbito educacional, o foco foi na LDB de 1996, que propiciou a expansão do ensino superior privado. Dentre as recomendações contempladas nesta legislação tem-se: conferir 
Barbosa TSC, Baptista SS. Movimento de expansão dos cursos superiores de enfermagem na região centro-oeste do Brasil: uma perspectiva histórica. Rev. Eletr. Enf. [Internet]. 2008;10(4):945-56. Available from: http://www.fen.ufg. br/revista/v10/n4/v10n4a07.htm.

maior autonomia às Instituições de Ensino Superior na definição dos currículos de seus cursos, através da organização de um modelo pedagógico capaz de adaptar-se à dinâmica das demandas da sociedade, em que a graduação, passa a constituir-se numa etapa de formação inicial no processo contínuo de educação permanente; e propor uma carga horária mínima em horas que permita a flexibilização do tempo de duração do curso de acordo com a disponibilidade e esforço do aluno.

Vale dizer que, a autonomia universitária que se refere à LDB ao ser aplicada segundo o entendimento dos "empresários da educação" representa liberalidade total para a criação de novos cursos e formatação dos "tradicionais" (dentre eles, o curso de enfermagem), uma vez que os critérios estabelecidos para a aprovação de cursos são extremamente facilitadores.

É importante ressaltar que a política neoliberal concretizada em nosso país, particularmente durante o governo de FHC, trouxe profundas mudanças na educação, uma vez que a reforma educacional, de forte marca economicista e tecnocrática, retirou a educação da esfera dos chamados direitos da cidadania e a colocou como um serviço disponível no mercado. Além disso, as universidades públicas sofreram forte impacto vendo 0 seu sucateamento através dos cortes de verbas, da não abertura de concursos públicos para professores e funcionários técnicoadministrativos, da continuidade da expansão do ensino superior privado e das matrículas dela decorrente, da destinação de verba pública para as faculdades particulares e da ausência de uma política efetiva de assistência estudantil ${ }^{(18)}$.

Outro fator no governo de FHC que também contribuiu para a consolidação da política de privatização do ensino superior foi o Fundo de Financiamento ao Estudante de Ensino Superior (FIES), instituído pela Medida Provisória no 1.827/99, de 27 de maio de 1999, e regulamentado pela Portaria MEC no 860 da mesma data. Tal programa foi criado para substituir o extinto Creduc e se baseia na mesma lógica do seu antecessor: o financiamento estudantil, por parte do governo federal, nas instituições superiores privadas.
Em decorrência das políticas adotadas pelos governos é possível perceber o crescimento do ensino superior privado. No caso da enfermagem, somente na década de 90, foram criados em todo o Brasil noventa e quatro cursos superiores; dos quais, setenta e sete $(82 \%)$ eram privados e dezessete (18\%) públicos. Em comparação com os vinte e um cursos de enfermagem privados criados nos anos 80 percebe-se que este novo número (77) quase triplicou ${ }^{(13)}$.

Assim, a distribuição dos cursos de enfermagem criados no Brasil até o final do ano de 1999 era a seguinte: Sudeste com cento e onze $(52,9 \%)$ cursos - $83 \%$ deles privados e $17 \%$ públicos; Sul com quarenta e quatro $(20,9 \%)$ - $73 \%$ privados e $27 \%$ públicos; Nordeste com trinta e um $(14,8 \%)$ cursos $71 \%$ públicos e $29 \%$ privados; Centro-Oeste com quatorze $(6,7 \%)$ - $57 \%$ privados e $43 \%$ públicos e Norte com dez $(4,8 \%)$ cursos de enfermagem - $60 \%$ públicos e $40 \%$ privados $^{(13)}$.

É importante destacar que, somente após um longo espaço de tempo, desde a criação em 1975 dos últimos cursos de enfermagem no Centro-Oeste, e sob a influência das políticas de educação nacional é que são criados nesta região mais oito cursos superiores de enfermagem, sendo cinco deles (62,5\%) privados e três $(37,5 \%)$ públicos; distribuídos regionalmente da seguinte forma: três públicos ( 2 federais e 1 estadual) no estado de Mato Grosso do Sul; dois privados no Distrito Federal; dois privados em Goiás e um, privado, no Mato Grosso ${ }^{(13)}$.

Foi com esta configuração que a região Centro-Oeste encerrou o século XX, ou seja, com a criação de apenas 14 cursos superiores de enfermagem em um período de sessenta e seis anos, tendo como referência a criação da primeira escola na região em 1933.

\section{AJ USTANDO-SE AO NOVO MI LÊNI O: 2000 - 2006}

Ainda no segundo mandato do presidente FHC, foi aprovado, através da Lei no 10.172, de 9 de janeiro de 2001, o Plano Nacional de Educação com diretrizes e metas para os próximos dez anos, cujos principais objetivos 
são: a elevação global do nível de escolaridade da população; a melhoria da qualidade do ensino em todos os níveis e a redução das desigualdades sociais e regionais, no tocante ao acesso e à permanência na educação pública ${ }^{(19)}$. Entretanto, no que concerne à educação superior, tal Plano privilegiou o setor privado, uma vez que reforçou que a política de expansão do ensino superior no país se dará preferencialmente através da ampliação das vagas nas instituições privadas, em conformação com o projeto neoliberal.

No ano de 2003 tomou posse como presidente do Brasil Luís Inácio Lula da Silva, que para o mesmo cargo foi reeleito no ano de 2006. Este, a princípio, se posicionava contra as políticas neoliberais, no entanto, percebe-se que o seu governo muito se assemelha ao anterior.

Durante o primeiro mandato do presidente Lula (2003-2006) foi elaborado o Projeto de Lei da Reforma Universitária (que está em tramitação no Congresso Nacional), antecedido por quatro leis e um decreto, que apontam mais para a continuidade do que para a descontinuidade das políticas anteriores no setor. O destaque se dá à Lei no 11.096 , de 13 de janeiro de 2005, que instituiu o Programa Universidade para Todos (PROUNI). Este programa regulamenta a "compra" das vagas ociosas nas instituições privadas, destinando, desta forma, verba pública para o setor e ainda isenção de um conjunto de impostos ${ }^{(20)}$.

Vale dizer que as políticas adotadas pelo governo federal no Brasil incentivaram o crescimento do setor privado. $\mathrm{Na}$ área de ensino em enfermagem esta tendência é clara, tanto que dos quinhentos e sessenta cursos superiores existentes no Brasil no ano de 2006, quatrocentos e setenta e um (84\%) eram privados e somente oitenta e nove (16\%) públicos. E especificamente na região CentroOeste, observa-se que de 2000 a 2006, isto é, em apenas sete anos, houve a criação de trinta cursos superiores de enfermagem o que perfaz um total de quarenta e quatro cursos criados na região até o final de 2006, dos quais trinta e cinco $(79,5 \%)$ eram privados e nove $(20,5 \%)$ públicos $^{(13)}$.

Com relação à distribuição destes quarenta e quatro cursos de enfermagem, temos: o estado de Goiás com dezessete $(38,6 \%)$ cursos, dos quais $88,2 \%$ eram privados e $11,8 \%$ públicos; Distrito Federal com dez $(22,7 \%)$, sendo $90 \%$ privados e $10 \%$ públicos; Mato Grosso com nove $(20,5 \%)$, dos quais $66,7 \%$ eram privados e $33,3 \%$ públicos e Mato Grosso do Sul com oito $(18,2 \%)$ cursos, $62,5 \%$ privados e $37,5 \%$ públicos ${ }^{(13)}$.

Como justificativa para o aumento considerável de cursos superiores de enfermagem privados no Centro-Oeste a partir do ano 2000 tem-se, além da política nacional de educação, a carência de enfermeiros na região, sendo as vagas existentes nas instituições de saúde preenchidas por profissionais que se formavam em outros estados; o mercado de trabalho em expansão, principalmente, na rede privada e no Programa Saúde da Família; a busca, por parte das esferas estaduais, da consolidação dos princípios do Sistema Único de Saúde - SUS, previstos na Lei $8080 / 90$ e a tentativa de diminuir o êxodo dos jovens que concluem o ensino médio e buscam o ensino superior em centros maiores, dificilmente retornando para sua região de origem.

\section{CONCLUSÃO}

No Brasil como um todo, a expansão do número de cursos de enfermagem ocorreu a partir de determinantes sociais, políticos e econômicos, acompanhando as políticas educacionais e de saúde.

Quanto à região Centro-Oeste, pode-se dizer que os três primeiros cursos superiores de enfermagem foram criados para atender a necessidade de um serviço de enfermagem capacitado nos hospitais religiosos inaugurados na região. Estes cursos, mantidos por congregações religiosas, que em sua maioria ofereciam cursos gratuitos, eram os únicos responsáveis, no período, pela formação de enfermeiros na região.

$\mathrm{Na}$ década de 70, embora tenham sido criados mais três cursos superiores de enfermagem no Centro-Oeste (todos mantidos por instituições públicas), tendo como pano de fundo o Plano Decenal de Saúde para as Américas, verificou-se que o movimento de expansão dos cursos de enfermagem na região 
Barbosa TSC, Baptista SS. Movimento de expansão dos cursos superiores de enfermagem na região centro-oeste do Brasil: uma perspectiva histórica. Rev. Eletr. Enf. [Internet]. 2008;10(4):945-56. Available from: http://www.fen.ufg.br/revista/v10/n4/v10n4a07.htm.

não seguiu o mesmo ritmo de outras regiões do Brasil (Sudeste, Sul e Nordeste); atribuímos a isto, o fato do Centro-Oeste possuir uma extensa área territorial cujo desenvolvimento teve maior impulso somente nas décadas de 30, 50 e 60, com o Programa "Marcha para o Oeste", com a criação de Brasília e da SUDECO.

A partir da década de 90, em decorrência das políticas neoliberais e das novas políticas da educação nacional, observa-se a criação de trinta e oito cursos de enfermagem no CentroOeste, sendo trinta (79\%) privados e oito (21\%) públicos, o que perfaz um total de quarenta e quatro cursos superiores de enfermagem criados até o final do ano de 2006.

Nestes dados merece destaque 0 crescimento do setor privado favorecido pelos incentivos diretos $e$ indiretos do governo federal; pois, se ao final de 1989 haviam sido criados seis cursos de enfermagem na região, três deles privado, ao final de 2006 o número total de cursos criados passa para quarenta e quatro, dois quais agora trinta e cinco são privados $(79,5 \%)$ e nove públicos $(20,5 \%)$.

Ainda que a região Centro-Oeste detenha, atualmente, um dos menores números de cursos de enfermagem no país, $8 \%$ do total, vale destacar a prevalência do setor de ensino privado, que ao nosso entendimento, acaba por determinar, quase que por completo, o perfil dos futuros profissionais de enfermagem a serem inseridos no mercado de trabalho em saúde.

\section{REFERÊNCIAS}

1. Fernandes JD. O sentido político, ideológico e econômico da expansão das escolas de enfermagem. Revista Baiana de Enfermagem. $1983 ; 1(1): 62-72$.

2. Baptista SS, Barreira IA. Condições de surgimento das escolas de enfermagem brasileiras. Revista Alternativa de Enfermagem. 1997; (2): 4-17.

3. Costa LCA, Mello LIA. História do Brasil. 11ạ edição. São Paulo: Scipione; 1999.

4. Ferreira HJ. Anápolis: sua vida, seu povo. 1a edição. Brasília: Gráfica do Senado Federal; 1979.

5. Ministério da Saúde; Serviço Especial de Saúde Pública. Enfermagem: Leis, decretos e portarias. 2a edição. Rio de Janeiro (Brasil): SESP; 1959.
6. Portal da Igreja Presbiteriana do Brasil [Internet]. Rio Verde: Igreja Presbiteriana do Brasil (GO) [update 2006 nov 13, cited 2006 nov 13]. Hospital Presbiteriano Dr. Gordon. Available from: http://www.ipb.org.br/acao social/hpg.php3.

7. Garfield S. As raízes de uma planta que hoje é o Brasil: os índios e o Estado-nação na era Vargas. Rev. bras. Hist. [Internet]. 2000 [cited 2007 mar 03];20(39):15-42. Available from: http://www. scielo.br/pdf/rbh/v20n39/2980.pdf.

8. Bezerra MRM. A enfermagem e a Aliança da Igreja com o estado: Escola de Enfermeiras Luiza de Marillac [dissertation]. Rio de Janeiro: Escola de Enfermagem Anna Nery/UFRJ; 2002. $53 \mathrm{p}$.

9. O Brasil e suas regiões [Internet]. Brasil: Brasil em foco (BR) [update 2008 set 06, cited 2008 set 06]. Goiás. Available from: http://www.tecsi.fea.usp. br/eventos/Contecsi20 04/BrasilEmFoco/port/divpol/centro/go/apresen t/index.htm.

10. Prefeitura Municipal de Porto Velho [Internet]. Porto Velho: Prefeitura Municipal de Porto Velho (RO) [update 2006 out 27, cited 2007 mar 02]. Os Documentos Legais. Available from:

http://www. portovelho.ro.gov.br/index2.php?op tion $=\mathrm{com}$ content\&do $\mathrm{pdf}=1 \& \mathrm{id}=6$.

11. Medeiros M, Tipple ACV, Munari DB. A expansão das escolas de enfermagem no Brasil na primeira metade do século XX. Revista Eletrônica de Enfermagem [Internet]. 1999 [cited 2006 nov 12];1(1). Available from: http://www.fen.ufg. br/revista/revista1_1/11.06 $.2008 / 04 . \mathrm{htm}$.

12. Abreu S. Planejamento governamental: a SUDECO no espaço Mato-Grossense, contexto, propósito e contradições [thesis]. São Paulo: Faculdade de Filosofia, Letras e Ciências Humanas/USP; 2001. 328 p.

13. Portal SiedSup [Internet]. Brasília: Ministério da Educação (BR) [update 2007 jan 20, cited 2007 jan 20]. Ensino superior: cursos e instituições. Available from: http://www. educacaosuperior.inep.gov.br.

14. Paim L. A formação de enfermeiros no Brasil na década de 70 . Rev Bras Enferm. 2001; 53(4): 185-96.

15. Mato Grosso do Sul [Internet]. Campo Grande: Potyguar (BR) [update 2007 mar 02, cited 2007 mar 02]. Uma trajetória divisionista. Available from: http://potyguar.com.br/matogrossodosul/. 16. Fundação Cultural do Estado do Tocantins [Internet]. Palmas: Governo do Estado do Tocantins (BR) [update 2008 set 06, cited 2008 
Barbosa TSC, Baptista SS. Movimento de expansão dos cursos superiores de enfermagem na região centro-oeste do Brasil: uma perspectiva histórica. Rev. Eletr. Enf. [Internet]. 2008;10(4):945-56. Available from: http://www.fen.ufg. br/revista/v10/n4/v10n4a07.htm.

set 06]. Trajetória de luta pela criação do Tocantins. Available from: http://cultura.to.gov.br/conteudo.php?id=94.

17. Sampaio H. Ensino superior no Brasil: o setor privado. São Paulo: Hucitec/FAPESP; 2000.

18. Figueiredo ESA. Reforma do ensino superior no Brasil: um olhar a partir da história. Revista da UFG [Internet]. 2005 [cited 2006 abr 23]; AnoVII (2): Dez. Available from: http://www.proec.ufg. br/revista_ufg/45anos/Creforma.html.

19. Ministério da Educação. Lei № 10.172 de 2001. Plano Nacional de Educação. Brasília: Ministério da Educação (Brasil); 2001.

20. Sguissardi V. Reforma universitária no Brasil - 1995-2006: precária trajetória e incerto futuro. Educ. Soc. [Internet]. 2006 [cited 2007 fev 15];27(96):1021-56. Available from: http://www.scielo.br/pdf/es/v27n96/a18v2796. pdf.

Artigo recebido em 11.10.07.

Aprovado para publicação em 31.12.08. 